\title{
Ultrafast acting insulin analog - a new way to prevent postprandial hyperglycemia and improve quality of life in type 1 diabetes patients - case reports
}

Ultraszybkodziałający analog insuliny - nowy sposób zapobiegania hiperglikemii poposiłkowej i poprawy jakości życia chorych na cukrzycę typu 1 - opis przypadków

\author{
Iwona Pietrzak, Agnieszka Szadkowska
}

Department of Pediatrics, Oncology, Haematology and Diabetology, Medical University of Lodz, Poland

\begin{abstract}
The aim of modern insulin therapy used in the treatment of type 1 diabetes mellitus is to mimic the physiological secretion of insulin in order to ensure stable normoglycemia while maintaining the greatest possible comfort of life for diabetic patients. New ultra-fast insulin analogs that can be administered immediately before a meal contribute to the improvement of postprandial glycemia and the quality of life of patients. We presented two cases illustrating the effectiveness and safety of the use of an ultra-fast-acting insulin analog in the treatment of postprandial hyperglycemia in children with type 1 diabetes.
\end{abstract}

Key words:

type 1 diabetes mellitus, postprandial hyperglycemia, time in range, ultrafast-acting analog of insulin, children.

\section{Streszczenie}

Celem nowoczesnej insulinoterapii stosowanej w leczeniu cukrzycy typu 1 jest naśladowanie fizjologicznego wydzielania insuliny w celu zapewnienia stabilnej normoglikemii przy zachowaniu jak największego komfortu życia chorych na cukrzycę. Nowe ultraszybkie analogi insuliny, które można podawać bezpośrednio przed posiłkiem, przyczyniają się do poprawy glikemii poposiłkowej i jakości życia pacjentów. W pracy przedstawiono dwa przypadki ilustrujące skuteczność i bezpieczeństwo zastosowania ultraszybkodziałającego analogu insuliny w leczeniu hiperglikemii poposiłkowej u dzieci z cukrzycą typu 1.

\section{Słowa kluczowe:}

cukrzyca typu 1, hiperglikemia poposiłkowa, czas w zakresie docelowym, ultraszybkodziałający analog insuliny, dzieci.

\section{Introduction}

The main goal of treating patients with type 1 diabetes (T1D) is to prevent acute and chronic complications of the disease and to ensure their quality of life as closely as possible to healthy people [1, 2].

The insulin formulations, as well as the methods and devices for its administration, serve to restore the physiological rhythm of insulin secretion in order to prevent dysglycemia. Not only chronic hyperglycemia, frequent hypoglycemia, but also higher glycemic variability lead to a higher risk of chronic complications of diabetes [3]. One of the best examples of shortterm glycemic variability is the postprandial glucose (PPG) increase $[4,5]$. Elevated PPG result in increased mean glycemia and $\mathrm{HbA}_{1 \mathrm{c}}$. They are also associated with increased oxidative stress and influence cardiovascular risk to a greater extent than fasting plasma glucose (FPG) [6]. For these reasons, efforts to limit excessive increases in PPG have become one of the most important challenges in modern diabetology [7].

The pharmacological profiles of subcutaneous administered prandial insulin should closely mimic the endogenous prandial insulin secretion pattern that is seen in individuals without diabetes. This idea has guided the developers of rapidacting insulin analogs (lispro - Eli Lilly, aspart - Novo Nordisk, glulisine - Sanofi), available for 25 years, which have an earlier onset and shorter duration of action than regular human insulin [8]. Hexamers of regular human insulin in subcutaneous tissue dissociate into dimers and then monomers to be absorbed. Modification of the B-chain structure of the insulin molecule results in faster dissociation to monomers, faster absorption and action [9]. The use of rapid-acting analogs in functional intensive insulin therapy of T1D patients help better match postprandial glucose excursion [10]. Despite faster absorption of rapid acting insulin from subcutaneous tissue, the physiological 
postprandial insulin response is not fully mimicked, resulting in still elevated PPG $[7,11]$. Attempts to prevent postprandial hyperglycemia by increasing the dose of rapid-acting analog insulin are associated with a risk of delayed hypoglycemia in the post meal period. The only effective solution is to recommend administration of a rapid-acting insulin analog 15-20 min before the start of a meal, which results in smaller PPG fluctuations and a longer time spent in the glucose target range (70-180 mg/dl), without an increased risk of hypoglycemia [7]. Clinical experience and the results of many studies indicate that diabetic patients often administer prandial insulin just before or even after eating a meal $[12,13]$. Synchronizing insulin administration with its expected effect on meal-derived glucose absorption is challenging for many people with diabetes, especially children. Lane et al. surveyed more than 1400 adults with T1D, 350 parents of children with T1D, and 960 experienced diabetes clinicians to examine attitudes and behaviors related to meal insulin administration. They found that $91 \%$ of adults with T1D and $97 \%$ of parents of children with T1D found the need to administer insulin before meals to be challenging [14]. Many adults with T1D (67\%) and parents of children with T1D (72\%) said that being able to administer bolus insulin immediately before or even after the start of a meal, rather than 15-20 minutes before eating, would benefit their quality of life.

Hence, the idea of developing ultrafast-acting analogs (also called "second-generation" analogs), which, due to their faster absorption from the subcutaneous injection site, would have an action profile more similar to physiological endogenous prandial insulin secretion and would inhibit endogenous glucose production to a greater extent after the meal [15]. Compared with rapid-acting insulin analogs, second-generation analogs would be expected to offer the possibility of more flexible prandial insulin use and contribute to improved postprandial glycemia, while maintaining the same safety profile. Fast-acting analog have been modified by adding an excipient that destabilizes the insulin hexamers, accelerating their dissociation to dimers and monomers [16]. Second-generation rapid-acting analogues include fast-acting aspart (Faster aspart, Novo Nordisk, Denmark), ultra-rapid lispro (Ultar-rapid lispro, Eli Lilly, USA) and BioChaperone Lispro (Adocia, France) [17-19].

Faster aspart (Fiasp $\AA$ ), is a new formulation of insulin aspart (NovoRapid ( ) ), an analogue of human insulin where the proline in position B28 has been substituted with aspartate. Compared with insulin aspart, faster aspart was modified by adding two excipients - I-arginine (an amino acid) to ensure formulation stability and niacinamide (vitamin $B_{3}$ ) to increase the absorption rate following subcutaneous administration. Nicotinamide facilitates the formation of insulin dimers and monomers, but it is also credited with vasodilatory effects - vasodilation of capillaries and increased blood flow at the insulin injection site contributes to faster insulin absorption and action [20, 21].

Faster aspart is recommended to be administered prior to the meal (0-2 minutes), with the flexibility to administer up to 20 minutes after starting the meal in situations, when there is uncertainty about the meal intake. Its total duration of action is $3-5$ hours [22].
Fiasp was approved by the US Food and Drug Administration (FDA) for the treatment of diabetes in the US in August 2017. Currently, Fiasp can be used for insulin therapy in children aged 1 year and above, adolescents and adults, including pregnant and lactating women.

The positive decision took into account information on the faster aspart pharmacokinetic and pharmacodynamic properties and the results of nine Onset clinical trial series, which compared faster aspart with insulin aspart for efficacy and safety in in patients with diabetes [23-27].

Analysis of pharmacokinetic and pharmacodynamic parameters of faster aspart in adults with T1DM revealed a leftward shift in the pharmacokinetic and pharmacodynamic profiles of faster aspart versus to insulin aspart. After subcutaneous administration, faster aspart appeared in serum 4.9 min earlier and reached maximum concentration 9 min earlier than insulin aspart. Exposure within the first 30 min (early exposure) was twice as high with faster aspart versus insulin aspart. Faster aspart also showed a greater early hypoglycemic effect than insulin aspart - during the first 30 min, the hypoglycemic effect of faster aspart was $74 \%$ greater than that of insulin aspart (AUC from 0 to 30 min: 1.74, 95\% Cl: 1.47-2.10). In contrast, the total and maximal hypoglycemic effects of faster aspart and insulin aspart were found to be similar [20]. When faster aspart was administered by CSII (continuous subcutaneous insulin infusion), it was found that the onset of action of faster aspart was marked 11.1 min earlier, and the early hypoglycemic effect was twice that of insulin aspart [28]. The observed phenomenon may be an effect of the method of insulin administration itself (the smaller subcutaneous depot of CSIl-administered insulin promotes faster pharmacokinetics of faster aspart, and continuous subcutaneous delivery of nicotinamide increases the rate of insulin hexameter dissociation) [29].

The results of clinical trials comparing the efficacy and safety of faster aspart (pre- or post-meal) and insulin aspart (pre-meal) in patients with T1D treated with MDI (multiple dose insulin) indicated that pre-meal Fiasp had a more favorable effect on PPG and $\mathrm{HbA}_{1 \mathrm{c}}$ and the risk of late postprandial hypoglycemia (3-4 hours after a meal). Post-meal administration of faster aspart had comparable metabolic effects to pre-meal administration of insulin aspart, however worse than pre-meal administration of faster aspart [27]. Total PPG is influenced not only by glucose delivered with a meal (75\% in healthy subjects), but also by endogenously produced glucose through glycogenolysis and gluconeogenesis (25\%). Faster aspart inhibits endogenous glucose production twice as strongly in the first 30 min after administration than insulin aspart [30].

Also, in T1D patients using CSII, faster aspart had a more favorable effect than insulin aspart on PPG growth with no greater risk of severe hypoglycemia [26].

Earlier than scheduled infusion set replacement was reported in $44 \%$ of patients receiving faster aspart and $16.7 \%$ of those treated with insulin aspart, while the incidence of unexplained hyperglycemia (considered a potential marker of infusion set obstruction), was comparable for faster aspart and insulin aspart. No microscopically confirmed occlusion was found in laboratory studies of infusion sets. Some patients using faster 
aspart reported infusion site reactions (including redness, inflammation, irritation, pain, bruising and itching), but these reactions are usually mild and transitory and they mostly disappear during continued treatment [25].

A study comparing the hypoglycemic effect of faster aspart and insulin aspart in children, adolescents, and adults found that in all age groups, the time to serum insulin emergence after subcutaneous injection was twice as short (5-7 minutes earlier) after faster aspart and early exposure was 78-147\% greater than with insulin aspart. Total exposure to faster aspart was lower in children and adolescents than in adults. Use of faster aspart in children compared with insulin aspart was metabolically preferable because it was associated with a smaller increase in PPG measured 2 hours after a meal. Faster aspart was as well tolerated as insulin aspart with no serious adverse events [31].

In a multicenter, randomized trial in children with T1D (1-18 years), faster aspart given before or given after a meal was no worse than insulin aspart in terms of its effect on change in $\mathrm{HbA}_{1 \mathrm{c}}$ from baseline. However, faster aspart given before a meal had a more favorable effect than insulin aspart on the change from baseline in PPG measured one hour after a meal ( $p<0.01$ for all meals). There were no statistically significant differences in the incidence of severe hypoglycemia or hypoglycemia confirmed by blood glucose levels [32].

When evaluating the effect of anti-insulin aspart antibodies on total and free insulin aspart concentrations and on the pharmacokinetics of faster aspart and insulin aspart, it was found that in children and adolescents with T1D, although elevated anti-insulin aspart antibody titers are associated with higher total insulin aspart concentrations, this does not affect the faster hypoglycemic effect of either faster aspart or insulin aspart. Faster aspart retains its ultrafast pharmacokinetics regardless of the concentration of total or free insulin aspart [33].

In adults with T1D diabetes, use of faster aspart in Medtronic 670G (Hybrid Closed Loop System) personal insulin pump therapy with auto mode was associated with lower PPG one hour after the test meal and longer time spent in the target glycemic range (TIR - time in range: $70-180 \mathrm{mg} / \mathrm{dl}$ ) versus insulin aspart [34]. In adult T1D patients faster aspart in pump therapy with the MiniMed Advanced Hybrid Closed-Loop (AHCL) system, demonstrated greater overall TIR compared with insulin aspart and better postprandial glycemic parameters. No case of ketoacidosis or severe hypoglycemia was reported [35]. In contrast, when comparing glycemic control after moderate-intensity exercise and high-intensity exercise in adults with T1D using the MiniMed Advanced Hybrid Closed-Loop (AHCL) system using fast - acting insulin aspart or insulin aspart, there were no differences in TIR during and 24 hours post exercise [36].

Real-world trials are particularly important in assessing the efficacy and safety of a drug. The GoBolus study examined the efficacy of faster aspart in adult patients with T1D treated with multiple insulin injections and using intermittent-scanning continuous glucose monitoring (iscCGM). After 24 weeks of therapy, $\mathrm{HbA}_{1 \mathrm{c}}$ improved, time in the target range significantly increased (by $46.1 \mathrm{~min} /$ day), and time with glycemia 180-250 mg/dl (by $43.5 \mathrm{~min} /$ day) and with glycemia $>250 \mathrm{mg} / \mathrm{dl}$ (by $35.6 \mathrm{~min} /$ day) decreased. There was no change in hypoglycemia duration or mean daily insulin dose [37].

\section{Case report 1}

An 18-year-old girl with type 1 diabetes mellitus since the age of 10, was treated with continuous subcutaneous insulin infusion for 7 years. She used insulin pump MiniMed Veo ${ }^{\mathrm{TM}}$ (Medtronic), supported by continuous glucose monitoring (Free Style Libre; Abbott). No episodes of severe hypoglycemia and diabetic ketoacidosis were reported. The girl had no additional diseases.

During the visit at the outpatient clinic on 12 July 2020 she was diagnosed as overweight (BMI-91 pc for gender and age), her $\mathrm{HbA}_{1 \mathrm{c}}$ was $6.0 \%$.

She used rapid-acting insulin analog at a daily dose of $1.05 \mathrm{U} / \mathrm{kg} / \mathrm{d}$, basal/bolus ratio was 50\%/50\%. Mean glycemia was $132 \mathrm{mg} / \mathrm{dl}$, TIR - 75\%, CV (coefficient of variation) - 39.8\%. Metabolic control was satisfactory, but increased CV and postprandial hyperglycemia were observed, especially after meals consisting mainly of carbohydrates, i.e. after the breakfast and after the dinner. A rapid-acting insulin analog was changed to Fiasp. On October 5, 2020, during the on-line visit, the patient reported no episode of severe hypoglycemia or any changes/ symptoms related to the site of insulin administration. Fiasp was administered at $1.0 \mathrm{U} / \mathrm{kg} / \mathrm{d}$, basal/bolus ratio was $46 \% / 54 \%$. Metabolic control parameters for diabetes were: mean glyce$\mathrm{mia}-113 \mathrm{mg} / \mathrm{dl}, \mathrm{TIR}-84 \%$, CV - 33.2\%.

The use of Fiasp improved PPG values, as well as mean glycemia, TIR and TAR (time above range: > $180 \mathrm{mg} / \mathrm{dl}$ ) and CV (Fig. 1). The patient was satisfied with the shorter waiting time between prandial bolus and start of the meal.

\section{Case report 2}

A 10-year-old girl with type 1 diabetes mellitus since the age of 6 years was treated with a personal insulin pump from the onset of diabetes. There were no episodes of severe hypoglycemia and diabetic ketoacidosis. The child had no additional diseases.

On March 28, 2020 during the visit at the outpatient clinic $\mathrm{HbA}_{1 \mathrm{c}}$ was $6.1 \%$. Insulin therapy was conducted with an insulin pump MiniMed 640G (Medtronic) operating in SmartGuard mode. Patient was treated with rapid-acting analog insulin at a daily dose of $0.85 \mathrm{U} / \mathrm{kg} / \mathrm{d}$, basal/bolus ratio was $41 \% / 59 \%$. Mean glycemia was $118 \pm 44 \mathrm{mg} / \mathrm{dl}, \mathrm{TIR}-82 \%$, CV - 34\%. Metabolic control of diabetes was very good, but postprandial glucose levels were regularly high after the first meal. It turned out that in the morning before going to school, the child usually ate breakfast immediately after the meal bolus.

The insulin used was changed to Fiasp. After 2 months during the next visit Fiasp dose was $0.83 \mathrm{U} / \mathrm{kg} / \mathrm{d}$, basal/bolus ratio 41\%/59\%. CGM metrics showed similar results: a mean glycemia of $116 \pm 39 \mathrm{mg} / \mathrm{dl}, \mathrm{TIR}-83 \%$, CV - 33.4\%, however much lower prandial glucose after the breakfast was noted (Fig. 2). No injection site reactions were observed. No episode of severe hypoglycemia was noted. The girl and her parents were satisfied with not waiting several minutes for starting a meal after a prandial bolus. 


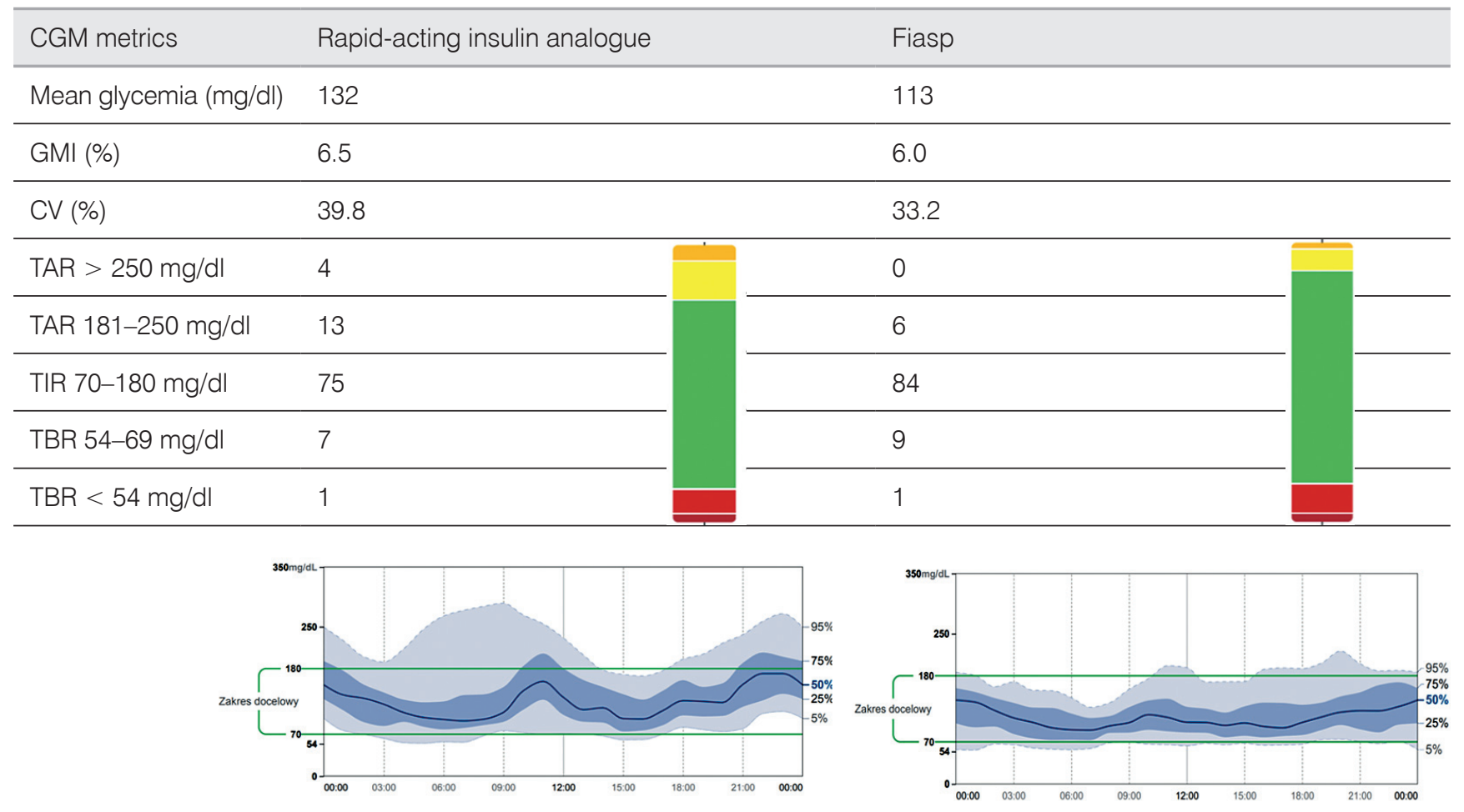

Figure 1. Case 1. Continuous glucose monitoring metrics during use of rapid-acting insulin analogue and during use of Fiasp

A

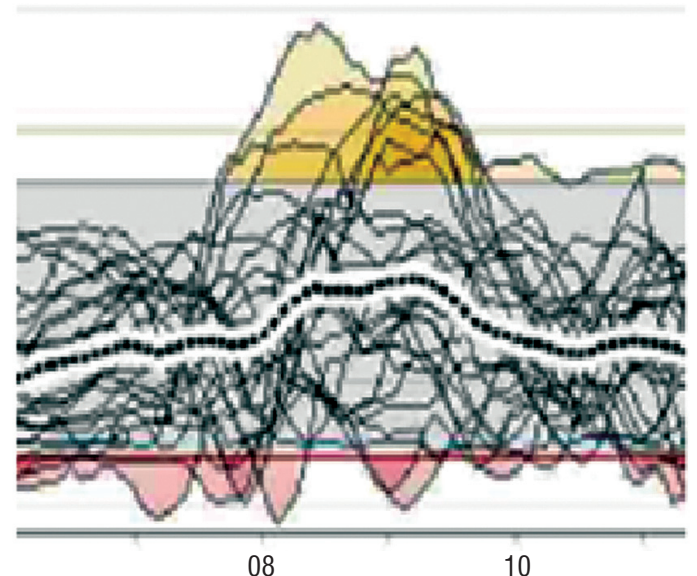

B

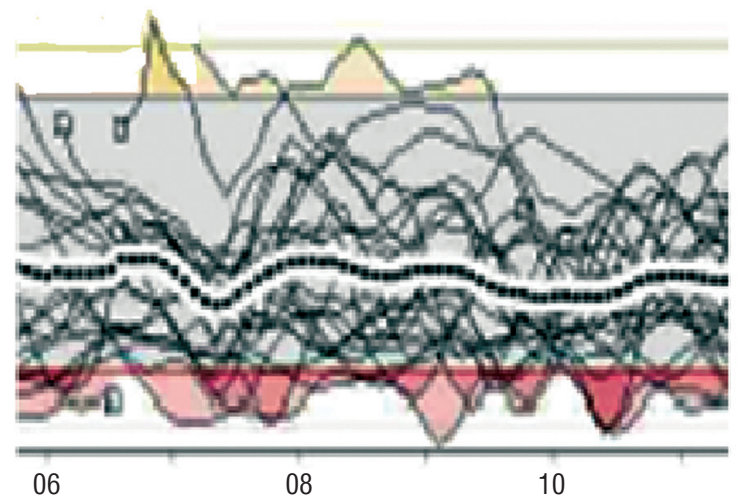

Figure 2. Case 2. Postprandial glucose after breakfast during use of rapid-acting insulin analog (A) and during use of Fiasp (B)

\section{Discussion}

The main causes of postprandial hyperglycemia are failure to match the dose of prandial insulin to the amount of carbohydrate contained in the meal, a meal consisting primarily of high glycemic index foods, and too short time between the administration of prandial insulin and the start of eating [38]. The use of an ultrafast-acting insulin analog immediately before a meal allows for a reduction in postprandial hyperglycemia without a greater risk of hypoglycemia [22].

For many patients using traditional rapid-acting insulin analogs, having to wait at least several minutes to eat a meal after a prandial bolus is a great inconvenience [14]. Therefore, the possibility of using an ultrafast-acting insulin analogue immediately before a meal without the risk of postprandial hyperglycemia contributes to an improved patient experience [37]. 
Based on the pharmacokinetic and pharmacodynamic properties of Fiasp and the results of clinical trials conducted with it, practical guidelines have been formulated for pump insulin therapy with the ultra-fast-acting insulin analogue [29]. Despite the recommendation to leave the current dosage in place when switching from aspart to Fiasp, clinical experience indicates that initiation of Fiasp insulin in CSII requires review of the pump settings and possible adjustment to the individual patient's needs.

In general, because of the accelerated absorption kinetics of faster aspart, the dose size and timing of the prandial bolus may need adjustment to reduce the risk of early postprandial hypoglycemia or late postprandial hyperglycemia. Early postprandial hypoglycemia is rare but can occur: after unexpectedly

\section{References}

1. Clinical recommendations for the management of patients with diabetes 2021. Statement of the Polish Diabetes Society. Clin Diabetol 2021; 10; 1-113

2. DiMeglio LA, Acerini CL, Codner E, et al. ISPAD Clinical Practice Consensus Guidelines 2018: Glycemic control targets and glucose monitoring for children, adolescents, and young adults with diabetes. Pediatr Diabetes 2018; 19 (Suppl 27): 105-114. doi: 10.1111/ pedi.12737.

3. Monnier L, Colette C. Glycemic variability: should we and can we prevent it? Diabetes Care 2008; 31 (Suppl 2): S150-S154. doi $10.2337 / \mathrm{dc0}$-s241

4. Nicolucci A, Ceriello A, Di Bartolo P, et al. Rapid-Acting Insulin Analogues Versus Regular Human Insulin: A Meta-Analysis of Effects on Glycemic Control in Patients with Diabetes. Diabetes Ther 2020; 11: 573-584. doi: 10.1007/s13300-019-00732-w.

5. Ceriello A, Monnier L, Owens D. Glycemic variability in diabetes: clinical and therapeutic implications. Lancet Diabetes Endocrinol 2019; 7: 221-230. doi: 10.1016/S2213-8587(18)30136-0.

6. DEDCODE Study Group and E.D.E. Group. Glucose tolerance and cardiovascular mortality: comparison of fasting and 2-hour diagnostic criteria. Arch Internal Med 2001; 161: 397. doi: 10.1001/ archinte.161.3.397.

7. Luijf YM, van Bon AC, Hoekstra JB, et al. Premeal injection of rapidacting insulin reduces postprandial glycemic excursions in type 1 diabetes. Diabetes Care 2010; 33: 2152-2155. doi: 10.2337/dc100692.

8. Home PD. The pharmacokinetics and pharmacodynamics of rapid-acting insulin analogues and their clinical consequences. Diabetes Obes Metab 2012; 14: 780-788. doi: 10.1111/j.1463-1326. 2012.01580.x.

9. Brange J, Owens DR, Kang S. Monomeric insulins and their experimental and clinical implications. Diabetes Care 1990; 13: 923-954 doi: 10.2337/diacare.13.9.923.

10. Fullerton B, Siebenhofer A, Jeitler K, et al. Short-acting insulin analogues versus regular human insulin for adults with type 1 diabetes mellitus. Cochrane Database Syst Rev 2016; 6: CD012161. doi: 10.1002/14651858.CD012161. delayed meals, after meals with high fat content, after carbohydrate counting errors, and in patients with gastroparesis.

The results of the cited studies and clinical experience indicate that administering Fiast before a meal has a more beneficial effect on PPG than administering it after a meal. Own experience showed that in case of high glycemic index meal bolus administration of Fiasp 15 minutes before a meal instead of immediately before a meal may further alleviate postprandial hyperglycemia.

In order to optimize the pharmacodynamic and pharmacokinetic properties of Fiasp in CSII therapy, optimization of basal rate should also be considered.

The use of continuous glucose monitoring, along with patient knowledge of the effect of meal composition and bolus type on PPG, may also facilitate optimal use of Fiasp in CSII [29]

11. Slattery D, Amiel SA, Choudhary P. Optimal prandial timing of bolus insulin in diabetes management: a review. Diabet Med 2018; 35: 306-331. doi: 10.1111/dme.13525.

12. Tamborlane WV, Pfeiffer KM, Brod M, et al. Understanding bolus insulin dose timing: the characteristics and experiences of people with diabetes who take bolus insulin. Curr Med Res Opin 2017; 33: 639-645. doi: 10.1080/03007995.2016.1275937.

13. Peters A, Van Name MA, Thorsted BL, et al. Postprandial dosing of bolus insulin in patients with type 1 diabetes: a cross-sectional study using data from the T1D Exchange registry. Endocr Pract 2017; 23: 1201-1209. doi: 10.4158/EP171813.OR.

14. Lane W, Lambert E, George J, et al. Exploring the Burden of Mealtime Insulin Dosing in Adults and Children With Type 1 Diabetes. Clinical Diabetes 2021; 39: 347-357. doi: 10.2337/cd20-0117.

15. Owens DR, Bolli GB. The continuing quest for better subcutaneously administered prandial insulins: a review of recent developments and potential clinical implications. Diabetes Obes Metab 2020; 22 : 743-754. doi: 10.1111/dom.13963.

16. Krasner A, Pohl R, Simms P, Pichotta P, et al. A review of a family of ultra-rapid-acting insulins: formulation development. J Diabetes Sci Technol 2012; 6: 786-796. doi: 10.1177/193229681200600408.

17. Shiramoto M, Nishida T, Hansen AK, et al. Fast-acting insulin aspart in Japanese patients with type 1 diabetes: Faster onset, higher early exposure and greater early glucose-lowering effect relative to insulin aspart. J Diabetes Investig 2018; 9: 303-310. doi: 10.1111/jdi.12697.

18. Blevins T, Zhang Q, Frias JP et al. Randomized Double-Blind Clinical Trial Comparing Ultra Rapid Lispro With Lispro in a Basal-Bolus Regimen in Patients With Type 2 Diabetes: PRONTO-T2D. Diabetes Care 2020; 43: 2991-2998. doi: 10.2337/dc19-2550.

19. Andersen G, Meiffren G, Lamers D et al. Ultra rapid BioChaperone Lispro improves postprandial blood glucose excursions vs insulin lispro in a 14-day crossover treatment study in people with type 1 diabetes. Diabetes Obes Metab 2018; 20: 2627-2632. doi: 10.1111/dom.13442.

20. Heise T, Pieber TR, Danne T, et al. A pooled analysis of clinical pharmacology trials investigating the pharmacokinetic and pharmacodynamic characteristics of fast-acting insulin aspart in adults with type 1 diabetes. Clin Pharmacokinet 2017; 56: 551-559. doi: 10.1007/s40262-017-0514-8. 
21. Kildegaard J, Buckley ST, Nielsen RH, et al. Elucidating the mechanism of absorption of fast-acting insulin aspart: The role of niacinamide. Pharm Res 2019; 36: 49. doi: 10.1007/s11095-019-2578-7.

22. Haahr H, Heise T. Fast-Acting Insulin Aspart: A Review of its Pharmacokinetic and Pharmacodynamic Properties and the Clinical Consequences. Clin Pharmacokinet 2020; 59: 155-172. doi: 10.1007/s40262-019-00834-5.

23. Mathieu C, Bode BW, Franek E, et al. Eficacy and safety of fastacting insulin aspart in comparison with insulin aspart in type 1 diabetes (onset 1): a 52-week, randomized, treat-to-target, phase III trial. Diabetes Obes Metab 2018; 20: 1148-1155. doi: 10.1111/ dom. 13205

24. Bowering K, Case C, Harvey J, et al. Faster aspart versus insulin aspart as part of a basal-bolus regimen in inadequately controlled type 2 diabetes: the Onset 2 Trial. Diabetes Care 2017; 40: 951957. doi: 10.2337/dc16-1770.

25. Zijlstra E, Demissie M, Graungaard T, et al. Investigation of Pump Compatibility of Fast-Acting Insulin Aspart in Subjects With Type 1 Diabetes. J Diabetes Sci Technol 2018; 12: 145-151. doi: $10.1177 / 1932296817730375$.

26. Klonoff DC, Evans ML, Lane W, et al. A randomized, multicentre trial evaluating the efficacy and safety of fast-acting insulin aspart in continuous subcutaneous insulin infusion in adults with type 1 diabetes (onset 5). Diabetes Obes Metab 2019; 21: 961-967. doi: 10.1111/dom.13610.

27. Buse JB, Carlson AL., Komatsu M, et al. Fast-acting insulin aspart versus insulin aspart in the setting of insulin degludec-treated type 1 diabetes: Efficacy and safety from a randomized doubleblind trial. Diabetes Obes Metab 2018; 20: 2885-2893. doi: 10.1111/dom. 13545

28. Heise T, Zijlstra E, Nosek L. et al. Pharmacological properties of faster-acting insulin aspart vs insulin aspart in patients with type 1 diabetes receiving continuous subcutaneous insulin infusion: A randomized, double-blind, crossover trial. Diabetes Obes Metab 2017; 19: 208-215. doi: 10.1111/dom.12803.

29. Evans M, Ceriello A, Danne T et al. Use of fast-acting insulin aspart in insulin pump therapy in clinical practice. Diabetes Obes Metab 2019; 21: 2039-2047. doi: 10.1111/dom.13798.

30. Basu A, Pieber T, Hansen AK, et al. Greater early postprandial suppression of endogenous glucose production and higher initial glucose disappearance is achieved with fast-acting insulin aspart compared with insulin aspart. Diabetes Obes Metab 2018; 20: 1615-1622. doi: 10.1111/dom.13270.

31. Fath M, Danne T, Biester T, et al. Faster-acting insulin aspart provides faster onset and greater early exposure vs insulin aspart in children and adolescents with type 1 diabetes mellitus. Pediatric Diabetes 2017; 18: 903-910. doi: 10.1111/pedi.12506.

32. Bode BW, lotova V, Kovarenko M et al. Efficacy and Safety of Fast-Acting Insulin Aspart Compared With Insulin Aspart, Both in Combination With Insulin Degludec, in Children and Adolescents With Type 1 Diabetes: The onset 7 Trial. Diabetes Care 2019; 42: 1255-1262. doi: 10.2337/dc19-0009.

33. Biester T, von dem Berge T, Bendtsen LQ, et al. The association between anti-insulin aspart antibodies and the pharmacokinetic and pharmacodynamic characteristics of fast-acting insulin aspart in children and adolescents with type 1 diabetes. Pediatr Diabetes 2020; 21: 781-790. doi: 10.1111/pedi.13026.

34. Ozer K, Cooper AM, Ahn LP, et al. Fast Acting Insulin Aspart Compared with Insulin Aspart in the Medtronic 670G Hybrid Closed Loop System in Type 1 Diabetes: An Open Label Crossover Study. Diabetes Technology \& Therapeutics 2021; 23: 286-292.

35. Lee MH, Paldus B, Vogrin S, et al. Fast-Acting Insulin Aspart Versus Insulin Aspart Using a Second-Generation Hybrid Closed-Loop System in Adults With Type 1 Diabetes: A Randomized, Open-Label, Crossover Trial. Diabetes Care 2021. doi: 10.2337/dc21-0814.

36. Morrison D, Zaharieva DP, Lee MH, et al. Comparable Glucose Control with Fast-Acting Insulin Aspart Versus Insulin Aspart Using a Second-Generation Hybrid Closed-Loop System During Exercise Diabetes Technol Ther 2021. doi: 10.1089/dia.2021.0221.

37. Danne T, Schweitzer MA, Keuthage W, et al. Impact of Fast-Acting Insulin Aspart on Glycemic Control in Patients with Type 1 Diabetes Using Intermittent-Scanning Continuous Glucose Monitoring Within a Real-World Setting: The GoBolus Study. Diabetes Technol Ther 2021; 23: 203-212. doi: 10.1089/dia.2020.0360.

38. Deeb A, Al Hajeri A, Alhmoudi I, et al. Accurate Carbohydrate Counting Is an Important Determinant of Postprandial Glycemia in Children and Adolescents With Type 1 Diabetes on Insulin Pump Therapy. J Diabetes Sci Technol 2017; 11: 753-758. doi: 10.1177/1932296816679850. 